\title{
Geradores de Mosaicos: cobrindo o plano através do software GeoGebra
}

\author{
Jéssica Carolini da Silva Laurindo - IM/PPGEMAT/UFRGS - jessica.rec@gmail.com \\ Lucas Caitano - IM/PPGEMAT/UFRGS - lucaitano@gmail.com
}

\begin{abstract}
Resumo
Neste artigo, apresentaremos uma proposta de atividade seguida de um relato de experiência com alunos da educação básica envolvendo arte, matemática e tecnologia através da construção do que chamamos de "Geradores de Mosaicos" no software GeoGebra. Desse modo, um dos objetivos dessa pesquisa é proporcionar um ambiente em que o aluno possa interagir com o software, desenvolvendo estratégias para criar diferentes Geradores de Mosaicos e, dessa forma, promover a aprendizagem por meio dessa construção. Nesse contexto, destacamos a potencialidade do uso da tecnologia sob o ponto de vista da teoria Construcionista. Além disso, salientamos o potencial do GeoGebra no que se refere conversão de representação de registros algébricos e geométricos contribuindo para a compreensão de conceitos matemáticos.
\end{abstract}

Palavras-chave: GeoGebra, computador, mosaico, registros de representação semiótica.

Mosaics Generators: covering the plane through the software GeoGebra

\begin{abstract}
In this article, we will present a proposal for activity followed by an account of experience with students of basic education involving art, mathematics and technology through the construction of what we call "Mosaics Generators" in GeoGebra software. Thus, one of the goals of this research is to provide an environment where students can interact with the software, developing strategies to create different mosaics generators and thus promote learning through this construction. In this context, it highlights the potential of using technology from the point of view of constructivist theory. In addition, we emphasize the potential of GeoGebra regarding conversion of algebraic and geometric representation records contributing to the understanding of mathematical concepts.
\end{abstract}

Kaywords: GeoGebra, computer, mosaic, semiotic representation of records. 


\section{Introdução}

Este artigo consiste na apresentação de uma proposta de atividade ${ }^{1}$ seguida de um relato de experiência realizada com alunos da educação básica. A atividade em questão envolve arte, matemática e tecnologia através da construção do que chamamos de "Geradores de Mosaicos" por meio da utilização de um software de matemática dinâmica.

Um dos objetivos desse estudo é proporcionar aos alunos a capacidade de criar estratégias em um software de matemática dinâmica para construir seus próprios mosaicos a partir da construção de uma figura geradora. Uma vez que essa figura é criada, o aluno poderá deformá-la de diferentes maneiras e automaticamente novos mosaicos serão criados. Nesse ambiente, os alunos serão desafiados a pensar sobre suas criações de um modo totalmente distinto do que se poderia obter apenas com desenhos coloridos em folhas de papel.

Por meio dessa atividade, os alunos poderão aprender importantes conceitos de geometria como, por exemplo: simetria, transformações geométricas (translação, rotação e reflexão) de figuras planas, polígonos, entre outros. Com isso, terão a oportunidade de perceber os inúmeros elementos geométricos presentes na criação e construção artística de mosaicos.

Para o desenvolvimento da atividade proposta foi utilizado o software GeoGebra. Este software é gratuito, multi-plataforma, disponível em diversos idiomas e pode ser usado em todos os níveis de ensino. Possui todas as ferramentas tradicionais de um software de matemática dinâmica, além de outros inúmeros recursos, possibilitando ao usuário um ambiente de criação e investigação por meio de diferentes registros compartilhados em uma mesma tela. Desse modo, um dos objetivos dessa pesquisa é investigar a potencialidade do software para a aprendizagem de conceitos matemáticos através da conversão de diferentes registros de representações semióticas.

O presente artigo foi estruturado do seguinte modo: na próxima seção será discutida a importância do computador no processo de aprendizagem dos estudantes a partir de uma perspectiva construcionista. Em seguida, apresentamos o software GeoGebra e suas potencialidades para promover a compreensão de conceitos matemáticos tomando como referencial teórico os Registros de Representação Semiótica de Raymond Duval. Na sequência, apresentaremos a proposta da atividade bem como a análise das produções dos alunos sujeitos dessa pesquisa sob o ponto de vista das conversões de registros de representação apresentadas em suas construções.

\section{O computador no processo de aprendizagem em Matemática}

$\mathrm{Na}$ década de 60, Seymour Papert começa a desenvolver uma série de ideias relacionadas à criação de ambientes educacionais baseados no uso da tecnologia. Suas ideias, inspiradas no Construtivismo de Piaget, com quem trabalhou, são conhecidas hoje como Construcionismo. Essa teoria de aprendizagem compartilha diversas concepções defendidas por Piaget, mas seu foco centra-se na tecnologia aplicada à educação e de que

\footnotetext{
1 A atividade proposta nesse artigo é inspirada no minicurso desenvolvido no XI Encontro Nacional de Educação Matemática (ENEM), em 2013, intitulado "Mosaicos, Faixas, Rosetas e Fractais com o Geogebra" dos autores Sérgio Carrazedo Dantas, Guilherme Francisco Ferreira, Maurício Barbosa da Silva e Sirlei Lopes da Silva.
} 
forma a tecnologia pode modificar a aprendizagem. Assim como o Construtivismo, o Construcionismo acredita que o desenvolvimento é um processo ativo de construção e reconstrução das estruturas mentais, no qual a figura do professor deixa de ser a do mestre explicador, aquele que transmite o conhecimento ao aluno, cujo único papel é o de receptor passivo. O papel do professor passa a ser o de provocador de situações que possibilitem que o aprendiz realize suas próprias descobertas. Ou seja, segundo essa teoria, o caminho para a aprendizagem e, por consequência, para o conhecimento, reside na concepção de que o aprendiz deve "colocar a mão na massa", considerando que este sujeito aprende e pensa mesmo sem ser "ensinado". Segundo o Construcionismo, aprende-se fazendo e aprende-se ainda mais quando se gosta do que se faz, se pensa e se conversa sobre isso. (MALTEMPI, 2004).

Partindo dessas ideias, Papert coloca na figura do computador o meio que viabiliza a criação de situações ricas e propícias para a construção do conhecimento.

Os PCN's reafirmam esse posicionamento, destacando que uma das finalidades do uso do computador nas aulas de Matemática é "auxiliar no processo de construção de conhecimento; como meio para desenvolver autonomia pelo uso de softwares que possibilitem pensar, refletir e criar soluções." (PCN, 1998, p.44).

Segundo o Construcionismo, o computador não deve ser apenas um recurso que oferece a compreensão através da visualização de objetos, mas sim um ambiente que possibilita, sobretudo, o pensamento e a criação. Nesse sentido o computador é, de acordo com Valente, um complicador:

O aprendiz tem de descrever para o computador todos os passos no processo de resolver um problema, fazer isso por intermédio de uma linguagem de computação e, se os resultados não correspondem ao que foi desejado, o aprendiz tem que adquirir a informação necessária, incorporá-la ao programa e repetir o ciclo descrição-execução-reflexãodepuração-descrição. Esse trabalho é complicador. (1999, p.82)

Diferente da tecnologia do lápis e do papel, ambientes computacionais propiciam que os estudantes realizem vários experimentos rapidamente, além de manipularem dinamicamente e visualizarem os objetos construídos favorecendo práticas investigativas sobre os conceitos matemáticos.

$\mathrm{Na}$ área da Educação Matemática há diversos autores que reforçam o potencial do uso das tecnologias de informação e computação frente ao processo de aprendizagem dos estudantes, tais como GRAVINA, SANTAROSA (1998), PENTEADO, BORBA (2003), MALTEMPI (2004), por exemplo. Esses autores, destacam a importância da incorporação dessas ferramentas na sala de aula, sob uma perspectiva que privilegie sobretudo a construção de conceitos através da tela do computador e apontam algumas possibilidades, apresentando propostas didáticas que fazem uso de recursos tecnológicos que transpõe a simples transmissão de conhecimentos.

Atualmente, dispõe-se de um vasto catálogo de softwares que permitem a realização de experimentos, simulações e até a criação de modelos, constituindo-se em ambientes de aprendizagem nos quais os estudantes podem programar o computador sem necessariamente utilizar uma linguagem de programação. Para Gravina e Santarosa (1998), nesses ambientes os alunos utilizam "processos de representação muito próximos dos processos de representação com "lápis e papel”, não lhes sendo exigido o 
conhecimento e domínio de uma nova sintaxe e morfologia, aspectos inerentes a uma linguagem de programação". Softwares algébricos e geométricos podem inserir-se no contexto em questão: os softwares algébricos, permitem realização de cálculos numéricos e a manipulação de expressões algébricas, assim como a criação de gráficos; os softwares de geometria dinâmica, por sua vez, possibilitam realizar construções em geometria e a manipulação dos objetos construídos dinamicamente. Há ainda, softwares que unem as características dos dois sistemas, algébrico e geométrico, expandindo as suas potencialidades frente às múltiplas construções que podem ser realizadas. O software de matemática dinâmica GeoGebra, por exemplo, apresenta recursos de cálculo, geometria e álgebra permitindo aos estudantes a criação, a visualização e a manipulação de objetos de modo dinâmico, além de possibilitar a elaboração de atividades que permitem a exploração e a investigação de conceitos matemáticos, assim como a realização de simulações por meio de uma linguagem simples.

$\mathrm{Na}$ próxima seção, serão apresentados os principais recursos disponíveis no software GeoGebra e suas potencialidades de sua utilização no processo de ensino/aprendizagem de matemática tomando como aporte teórico os Registros de Representação Semiótica de Raymond Duval.

\section{O potencial do software GeoGebra à luz da teoria dos Registros de Representações Semióticas.}

Criado por Markus Hohenwarter o GeoGebra é um software livre de matemática dinâmica e vem despertando o interesse de muitos professores por reunir diversos recursos e apresentar diferentes representações do mesmo objeto que interagem entre si e que podem ser modificadas pelo usuário.

O programa apresenta uma janela de álgebra, no qual são exibidos os elementos algébricos referentes às construções realizadas pelo usuário; três janelas de visualização - duas para a visualização de objetos bidimensionais e uma para a visualização de objetos representados tridimensionalmente - nas quais são apresentados os elementos gráficos e geométricos criados; além de uma planilha eletrônica e uma janela CAS (Cálculo Algébrico Simbólico) que possibilita, por exemplo, a resolução de equações de forma simbólica. Ou seja, a diversidade de representações oferecidas pelo software permite a visualização e a manipulação simultânea de registros algébricos e geométricos e pode ajudar os estudantes a construírem novos significados para um mesmo conceito. Além disso, facilita o processo de conversão de diferentes registros de representações semióticas.

Duval define representações semióticas como "produções constituídas pelo emprego de signos pertencentes a um sistema de representações que tem inconvenientes próprios de significação e de funcionamento" (2012, p.269). Em Matemática, as figuras geométricas, as fórmulas algébricas, os gráficos e até mesmo os enunciados em língua natural são exemplos de diferentes tipos de representações que desempenham um papel fundamental para a compreensão de conceitos. Um mesmo objeto matemático, por sua vez, pode ser representado por meio de diferentes registros que obedecem determinadas regras de funcionamento e de tratamento. Uma equação, por exemplo, pode ser representada por meio de registros algébricos que, sob determinadas regras, levam a sua solução. Do mesmo modo, essa equação também pode ser representada graficamente 
através de sistemas de coordenadas cartesianas permitindo a identificação de novos elementos relativos ao comportamento da curva em questão.

Nesse sentido, Duval destaca que os registros de representações podem sofrer dois tipos de transformações: o tratamento, que consiste em transformações de representações no mesmo registro (por exemplo: resolução de uma equação); e a conversão, que consiste na mudança de registros conservando o mesmo objeto (por exemplo: a passagem de uma equação para a representação gráfica da mesma). Para o autor, "a compreensão em matemática supõe a coordenação de ao menos dois registros de representações semióticas" (2003, p.15). No entanto, parece que é nesse aspecto que os estudantes apresentam maiores dificuldades pois, em geral, mostram não compreender os diferentes registros que representam um mesmo objeto.

Desse modo, o software GeoGebra revela-se como um instrumento importante sob o ponto de vista da conversão de representações. Muitos conceitos podem ser explorados pelos estudantes a partir dos registros algébricos e geométricos compartilhados em uma mesma tela. Além disso, o software permite a modificação dessas representações pelo usuário, ou seja, ao modificar uma representação algébrica, automaticamente a representação geométrica também é modificada simultaneamente, possibilitando ao estudante a visualização e compreensão de diferentes significados sobre o mesmo objeto estudado.

A atividade descrita a seguir consiste na elaboração de um mosaico a partir de uma figura geradora. Para a elaboração desse mosaico, o estudante terá que criar uma lista de sequências através dos comandos oferecidos pelo software. A articulação entre o comando de sequência criado e o mosaico gerado estabelece o encontro de dois registros, algébrico e geométrico. Desse modo, os estudantes devem relacionar as diferentes representações estabelecidas nas construções por meio de sucessivas conversões de registros.

$\mathrm{Na}$ próxima seção, apresentamos os sujeitos envolvidos nessa pesquisa assim como a metodologia desenvolvida na proposta da atividade, seguida dos resultados obtidos a partir da análise dos registros dos estudantes sob a perspectiva da teoria de Duval.

\section{A atividade: mosaicos no GeoGebra}

Os mosaicos construídos nessa atividade são compostos por padrões repetidos de modo a cobrir o plano. Estes padrões poderão ter diferentes níveis de complexidade. Os mosaicos construídos são formados por polígonos (regulares e não-regulares). Desse modo, obteremos um tipo específico de mosaicos: aqueles obtidos a partir de polígonos utilizando transformações geométricas no plano. Para isso, propomos uma maneira de construção que denominamos "Geradores de Mosaicos", utilizando como recurso o software GeoGebra. Esse modo de construção possibilita que, através de uma única figura seja possível preencher o plano, criando, desse modo, um mosaico. Além disso, é possível deformar a figura original (geradora) transformando dinamicamente o mosaico criado. Ou seja, obtemos infinitos mosaicos em uma mesma construção. 


\subsection{Desenvolvimento da proposta}

A atividade proposta foi desenvolvida em dois encontros de aproximadamente três horas com sete estudantes do ensino médio do Colégio de Aplicação da Universidade Federal do Rio Grande do Sul (CAp UFRGS), no turno inverso ao de suas aulas. A faixa etária dos participantes dessa pesquisa é de 14 a 17 anos de idade. É importante destacar que a escolha desses alunos ocorreu por terem evidenciado interesse pela proposta apresentada, assim como pela etapa de escolarização que se encontravam, uma vez que a atividade envolvia conceitos desenvolvidos no ensino médio.

Destacamos, também, que cinco desses estudantes já haviam tido contato com o software GeoGebra em atividades desenvolvidas na disciplina de Matemática em anos escolares anteriores e, portanto, conheciam as ferramentas básicas do software. No entanto, antes de iniciarmos as construções dos mosaicos, mostramos brevemente a interface do software GeoGebra, assim como alguns recursos importantes do programa.

Uma vez compreendido o funcionamento do software, apresentamos os passos para a construção de um mosaico gerado por um polígono simples. Na ocasião, o mosaico em questão foi construído por uma figura geradora com a forma de um quadrado, conforme a figura 1. No entanto, podemos utilizar como ponto de partida qualquer polígono, sem que seja necessário modificar os passos da construção. Depois de criada a figura geradora, o mosaico foi construído a partir de sequências de translações horizontais e verticais (comandos "Sequência" e "Transladar") da figura geradora que são exibidas na janela de visualização 2 do software. Na figura a seguir podemos visualizar o resultado obtido:

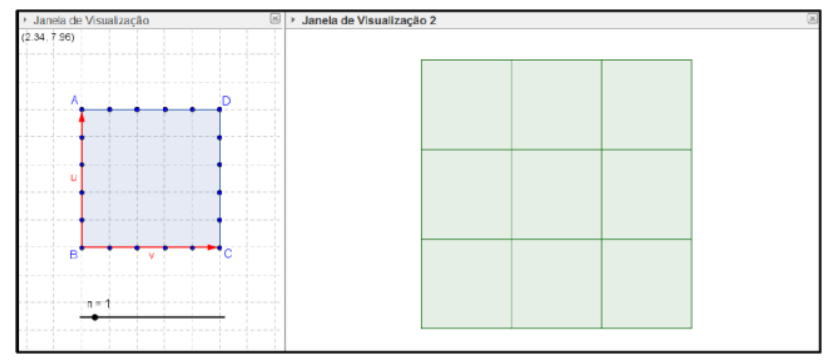

Figura 1 - Mosaico gerado a partir de um quadrado.

A construção descrita acima pode ser modifica de modo a obtermos mosaicos mais sofisticados a partir do movimento dos pontos que compõe o quadrado (figura geradora) e da alteração das cores das sequências de polígonos exibidos na janela de visualização 2. Além disso, é possível acrescentar outros polígonos à figura geradora ou, então, controles deslizantes que modificam as cores do mosaico dinamicamente.

Depois de apresentarmos os comandos para a criação de um mosaico simples, propomos aos estudantes a criação de mosaicos a partir de figuras geradoras constituídas por novos polígonos. No final, cada estudante deveria apresentar aos colegas os mosaicos criados, explicando os comandos utilizados.

Na segunda etapa da atividade, os estudantes foram convidados a criar novos mosaicos a partir de figuras que compõe algumas obras do artista Maurits Cornelis Escher. Os alunos deveriam utilizar a mesma ideia desenvolvida na primeira parte da atividade. A diferença encontra-se basicamente na figura geradora que agora passa a ser 
constituída pelas figuras que constituem a obra a ser reproduzida. A figura 2 ilustra o resultado obtido a partir da disposição das figuras geradoras e dos vetores de translação.

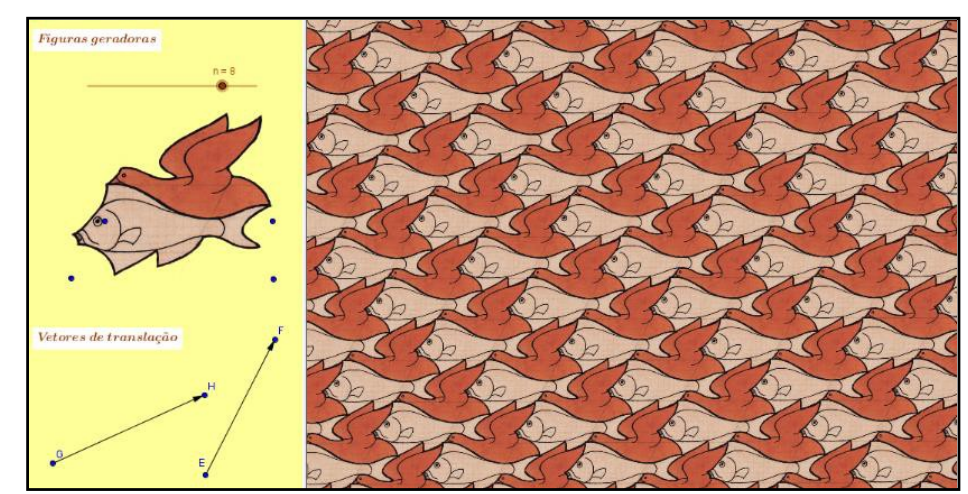

Figura 2 - Reprodução da obra Bird Fish através do software GeoGebra.

Na seção seguinte serão apresentados alguns resultados a partir da análise dos dados obtidos, apontando as dificuldades expostas pelos estudantes durante a criação dos mosaicos, bem como algumas possibilidades observadas com a atividade proposta.

\section{Resultados}

Ao analisarmos as construções dos mosaicos desenvolvidas pelos estudantes ao longo da atividade, observou-se que a função dos vetores foi pouco compreendida, uma vez que alguns não sabiam onde posicioná-los na figura geradora. Os alunos surpreenderam-se com a presença de vetores na construção, pois acreditavam que o mesmo estava relacionado apenas aos conceitos da Física. Ressaltamos, porém, que vetor é um elemento matemático e constitui-se em um representante do conjunto de segmentos orientados que possuem mesma direção, comprimento e sentido. No caso dos mosaicos, a função do vetor está associada a translação do polígono criado na janela de visualização. Para evidenciarmos esse conceito, mostramos através do comando "Transladar[pol,2u]" no GeoGebra que, ao multiplicarmos o vetor $u$ por dois, por exemplo, estaremos transladando o polígono pol duas vezes. Do mesmo modo, ao mudarmos a direção, o comprimento e o sentido do vetor, todos os polígonos gerados a partir do comando "Transladar" também serão alterados, como ilustra a figura 3.

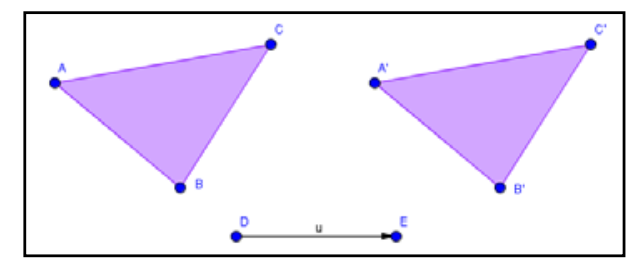

Figura 3 - Translação de um polígono a partir de um vetor.

Outro fator complicador foi a notação de vetor utilizada pelo software na janela de álgebra, pois os alunos reconheciam apenas a representação de um vetor como uma seta. Mostramos que no vetor $u=\left(\begin{array}{l}8 \\ 0\end{array}\right)$, por exemplo, o número oito representa a sua variação horizontal e o número zero representa a sua variação vertical. Neste instante, 
fica evidente o "enclausuramento" de registro ao que se refere a representação de vetores, uma vez que os estudantes apenas conseguiam relacioná-lo a uma seta. Desse modo, os alunos tinham dificuldade em reconhecer um mesmo objeto matemático em duas representações diferentes, algébrica e geométrica (DUVAL, 2003). Além disso, percebemos que a definição, caracterizada pela linguagem, também não foi suficiente para a compreensão dos alunos, necessitando recorrer a representação geométrica. Para Duval, "toda a representação é cognitivamente parcial em relação ao que ela representa, e que de um registro a outro não estão os mesmos aspectos do conteúdo de uma situação que estão representados" (2012, p.280). Torna-se, portanto, necessária a conversão de registros, fato esse que, segundo o autor, está intimamente ligada a compreensão em Matemática.

O processo de criação dos mosaicos está diretamente relacionado a conversão de diferentes registros. A todo momento era necessário representar as sequências de translações da figura geradora para a linguagem de programação especifica do software, no caso o comando "Sequência", de modo que o comando descrito seja representado geometricamente nas janelas de visualização. Este fato pode ser estendido especialmente aos momentos de criação das figuras geradoras.

Alguns alunos optaram por criar círculos para gerar seus mosaicos, no entanto, desconheciam a equação necessária para a construção do mesmo. Em particular, um estudante queria construir um círculo de raio 3. Então, foi apresentada a ferramenta disponível no GeoGebra intitulada "Círculo dados Centro e Raio", que permite a construção de um círculo com centro e raio determinados. Em seguida, foi apresentada a equação correspondente na janela de álgebra, que não foi compreendida pelo estudante pois, para ele, a equação correta deveria ser $?^{2}+?^{2}=3$. Fez-se necessário, portanto, a discussão acerca da representação algébrica. Ou seja, a aprendizagem de um conceito, nesse caso, surgiu a partir da necessidade de criar um círculo com raio específico.

Um aspecto importante a ser destacado foi a possibilidade de mostrar ao estudante que, ao modificar a medida do raio do círculo, a representação do registro algébrico e geométrico também eram alterados simultaneamente. Para Duval "passar de um registro de representação a outro não é somente mudar de modo de tratamento, é também explicar as propriedades ou os aspectos diferentes de um mesmo objeto" (2003, p.22). A figura 4, a seguir, ilustra o mosaico criado pelo estudante a partir de um círculo.

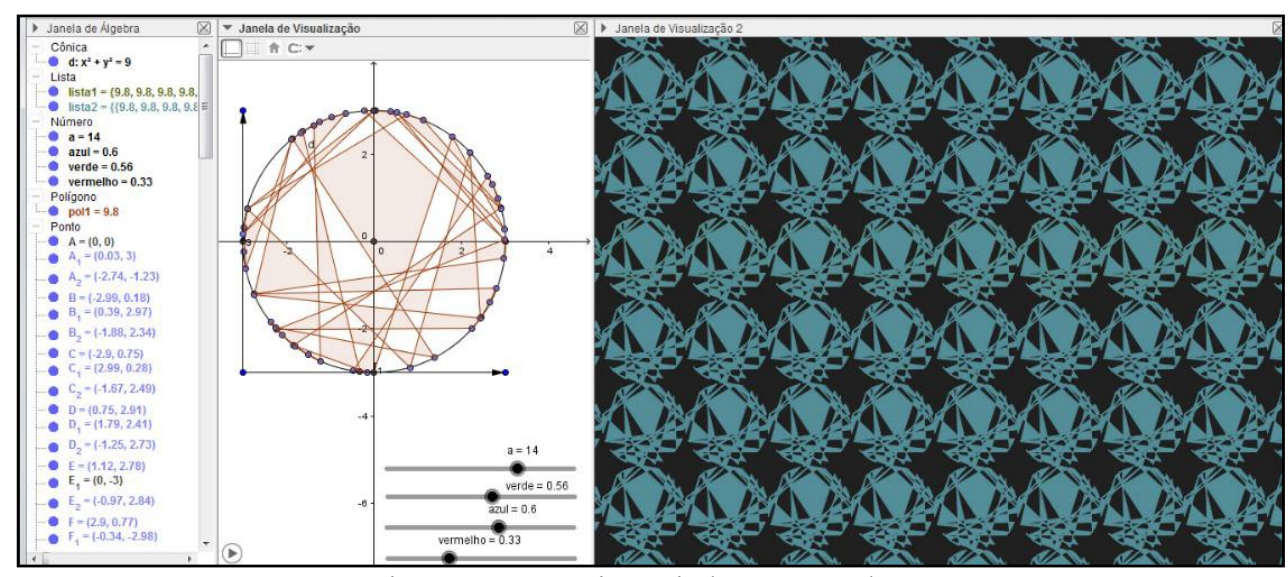

Figura 4 - Mosaico criado por um aluno. 
Nesta figura, fica evidente a diversidade de representações oferecidas pelo software. Uma vez que os pontos que compõe a figura geradora são movidos, todas as representações são modificadas simultaneamente na janela algébrica e nas janelas de visualização. Para Duval, "é a articulação dos registros que constitui uma condição de acesso à compreensão em matemática, e não o inverso, qual seja, o "enclausuramento" de cada registro". (2003, p. 22).

Novas figuras geradoras podem ser criadas através do comando "Girar" no GeoGebra. Com este comando é possível girar polígonos em torno de um ponto. Desse modo, propomos a elaboração de outros mosaicos associando esse recurso ao comando "Sequência". Assim, um estudante criou uma sequência de giros de um polígono em torno de um ponto utilizando a ferramenta "controle deslizante" para controlar o ângulo de giro do polígono. A compreensão das funções dos elementos que compõe o comando "Sequência", tornou possível a composição deste com o comando "Girar", gerando a rotação de uma coleção de polígonos em torno de um ponto, conforme a figura 5. Ou seja, o aluno controla as relações existentes entre as transformações de um mesmo registro algébrico ("tratamento") e entre o registro algébrico e seu efeito na representação geométrica através da janela de visualização.

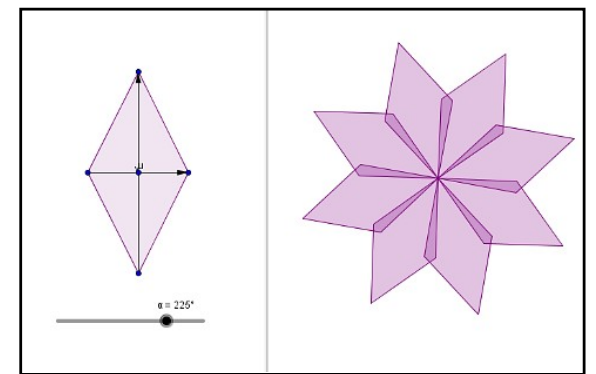

Figura 5 - Sequência de giros de um polígono.

\section{Conclusão}

Observando as produções dos estudantes envolvidos nesta pesquisa, percebemos que o GeoGebra constitui uma importante ferramenta para aprendizagem em matemática uma vez que os recursos disponibilizados pelo software contribuíram para a compreensão de conceitos por meio da conversão dinâmica e simultânea dos diferentes registros de representação presentes na janela algébrica e na janela gráfica.

É claro que poderíamos apresentar aqui outros argumentos relacionados aos conhecimentos matemáticos que os alunos poderiam adquirir através da atividade proposta. Esses argumentos serviriam para reafirmar o potencial da atividade, mas não expressariam tudo o que vislumbramos em atividades deste tipo. O objetivo é maior: não desejamos simplesmente uma maneira divertida de oferecer conceitos de geometria aos nossos alunos. O que objetivamos é a criação de um ambiente propício à aprendizagem no qual haja investigação e criação através da conexão entre diferentes conhecimentos, onde os alunos sintam a necessidade de pensar sobre o que estão produzindo.

Há quem não compreenda de que forma a tecnologia pode contribuir com o processo de aprendizagem, pois pensam que um software como o GeoGebra serve apenas para facilitar a visualização dos conceitos. Pensam: as ferramentas já estão pontas e basta usá-las. O aluno não precisa pensar e criar. Esta atividade vai à contramão desse 
posicionamento e, através dela, podemos perceber o potencial de recursos tecnológicos como o GeoGebra para modificar esse processo, possibilitando a criação de um ambiente de construção do conhecimento. Diferentemente da escola, que prioriza o ensino, cujas perguntas são pré-determinadas e possuem somente uma resposta correta, em um ambiente virtual como o possibilitado por atividades deste tipo, vários são os caminhos para chegarmos a vários fins.

\section{Bibliografia}

BRASIL, Secretaria da Educação Fundamental. Parâmetros Curriculares Nacionais: Matemática. Brasília: MEC, 1998.

DANTAS, S. C.; FERREIRA, G. F.; SILVA, M. B.; LOPES, S.. Mosaicos, faixas, rosetas e fractais com o GeoGebra. In: XI ENEM - Encontro Nacional de Educação Matemática, 2013, Curitiba. Anais do XI ENEM - Encontro Nacional de Educação Matemática, 2013

DUVAL, R. Registros de representações semiótica e funcionamento cognitivo da compreensão em matemática. In: Aprendizagem em matemática: registros de representação semiótica. Organização de Silvia Dias Alcântara Machado, p.11- 33. Campinas, São Paulo: Papirus, 2003.

DUVAL, R.. Registros de representação semiótica e funcionamento cognitivo do pensamento. Tradução de Méricles Thadeu Moretti. Revemat: R. Eletr. de Edu. Matem. Florianópolis, v. 07, n. 2, 2012. p.266-297.

GRAVINA, M. L.; SANTAROSA, L. M. A aprendizagem da matemática em ambientes informatizados. In:IV Congresso RIBIE, Anais. Brasília, 1998.

MALTEMPI, M. V. Construcionismo: pano de fundo para pesquisas em informática aplicada à Educação Matemática. In: BICUDO, M. A. V.; BORBA, M. C. (Org.). Educação Matemática: pesquisa em movimento. São Paulo: Cortez, 2004. p. 264-282.

PENTEADO, M. G.; BORBA, M. de C. Informática e Educação Matemática. Belo Horizonte: Autêntica, 2003.

VALENTE, J.A.. Análise dos Diferentes Tipos de Softwares Usados na Educação. In: JOSE ARMANDO VALENTE. (Org.). Analise dos Diferentes Tipos de Softwares Usados na Educação. 1ed. Campinas: Nied/Unicamp, 1999, v., p. 89-110. 